\title{
Changes of CD14 and CD1a Expression in Response to IL-4 and Granulocyte-Macrophage Colony-Stimulating Factor Are Different in Cord Blood and Adult Blood Monocytes
}

\author{
ENMEI LIU, WENWEI TU, HELEN K.W. LAW, AND YU-LUNG LAU \\ Department of Pediatrics, Faculty of Medicine, The University of Hong Kong, Queen Mary Hospital, \\ Pokfulam, Hong Kong, China [E.L., H.K.W.L., Y.L.L.], and Department of Pediatrics, Stanford University,
} Palo Alto, California 94306, U.S.A. [W.T.]

\begin{abstract}
Neonates are relatively immature in their immune response; thus, to further clarify the differences of monocyte function and differentiation between neonates and adults, we investigated their $\mathrm{CD} 14^{+} \mathrm{CD} 4^{+}$and $\mathrm{CD} 14^{+} \mathrm{CD} 16^{+}$monocyte subpopulations, production of IL- $1 \beta$ and tumor necrosis factor- $\alpha$ induced by lipopolysaccharide, and their CD14 and CD1a phenotypic changes in response to IL-4 and granulocyte-macrophage colony-stimulating factor. Our results showed that 1 ) the expression of CD14 in cord blood monocytes was significantly lower than that in adult peripheral blood monocytes; 2) both the percentages of $\mathrm{CD} 14^{+} \mathrm{CD}^{+}$cells and $\mathrm{CD} 14^{+} \mathrm{CD} 16^{+}$cells among $\mathrm{CD} 14^{+}$ monocytes were also significantly lower in cord blood; 3 ) after stimulation by lipopolysaccharide for $72 \mathrm{~h}$, production of both IL- $1 \beta$ and tumor necrosis factor- $\alpha$ was lower in cord blood than that in adult peripheral blood; and 4) in response to IL-4 or GM-CSF, the phenotype development of CD14 and CD1a in cord blood and adult peripheral blood was different. Downregulation of CD14 expression in response to IL-4 and GM-CSF was slower in cord blood monocytes than that in adult peripheral blood monocytes. After $9 \mathrm{~d}$ of culture in the presence of IL- 4 and
\end{abstract}

\section{ABSTRACT}

GM-CSF, the percentage of CD1a ${ }^{+}$monocytes was significantly more increased in cord blood than that in adult peripheral blood. The reduced expression of CD14 and other mature phenotype markers such as CD16 and CD4 as well as the reduced IL- $1 \beta$ and tumor necrosis factor- $\alpha$ production may contribute to the impaired immune response of neonates. Slower down-regulation of CD14 by IL-4 and GM-CSF suggests that differential properties of cord blood monocytes in response to cellular stress signals take a longer time than those of adult peripheral blood monocytes. (Pediatr Res 50: 184-189, 2001)
LPS, lipopolysaccharide
MNC, mononuclear cells
TNF- $\alpha$, tumor necrosis factor- $\alpha$
GM-CSF, granulocyte-macrophage colony-stimulating factor
DC, dendritic cells
PC5, phycoerythrin-cyanin 5.1
CBMC, cord blood mononuclear cells
PBMC, peripheral blood mononuclear cells

The monocyte plays an important role in host immunity. CD14, a glycoprotein of $55 \mathrm{kD}$ present on most monocytes and tissue macrophages, is regarded as the most important myeloid differentiation antigen $(1,2)$. Functionally, CD14 acts as a receptor for the complex of LPS and LPS-binding protein (3), and mediates the response to LPS, such as the LPS-induced production of the cytokines TNF- $\alpha$, IL- 6 , and IL- $8(3,4)$. The apoptosis of monocytes is associated with the down-regulation of CD14 expression (5), and CD14 is also a major receptor on

Received August 11, 2000; accepted February 21, 2001.

Correspondence and reprint requests: Yu-Lung Lau, M.D., Department of Pediatrics, Faculty of Medicine, The University of Hong Kong, Queen Mary Hospital, Pokfulam, Hong Kong, China; e-mail: lauylung@hkucc.hku.hk

Supported by a grant from the Research Grants Council of the Hong Kong Special Administrative Region, China (RCG No. HKU-7276/98M). phagocytes, which are involved in uptake of apoptotic cells (6). The expression of CD14 on PBMC is increased by LPS $(7,8)$ and decreased by IL-4 and GM-CSF (9-11). In vitro, with CD14 down-regulation in response to IL-4 and GM-CSF, $\mathrm{CD}_{14}{ }^{+}$monocytes can differentiate into cells displaying features of immature DC, which express CD1a (12).

The heterogeneity of human PBMC in terms of size, function, and antigen expression has been reported $(13,14)$. About $10 \%$ of the $\mathrm{CD}_{14}{ }^{+}$monocytes in peripheral blood express CD16, which is an Fc $\gamma 3$ receptor $(14,15)$. The $\mathrm{CD} 14^{+} \mathrm{CD} 16^{+}$ population represents more-mature monocytes and has higher antigen-presenting ability but lower phagocytic activity (16). Another antigen, CD4, is also expressed on a subpopulation of monocytes, which might be correlated with functional maturation of increased antigen-presenting capacity (17). 
Neonates are susceptible to infections because of their transient immaturity in T-cell, B-cell, and monocyte functions $(18-20)$. The chemotactic, phagocytic, and bactericidal properties of neonatal monocytes were reduced in comparison with those of adult monocytes (21-25). As for the monocyte subpopulations in neonates, there has been no consistent report. Mawas et al. (26) identified higher proportion of CD16 ${ }^{+}$ monocytes in neonates than that in adult control. Maeda et al. (27) also reported a small subpopulation of $\mathrm{CD} 16^{+}$monocytes in adult blood, which was absent or at a low level in cord blood; however, the main population of CBMC expressed low but higher levels of CD16 than adult monocytes. Kampalath et al. (28) reported that the percentage of monocytes displaying CD16 in cord blood did not show any significant difference in comparison with adult monocytes. In the same report, it was shown that CD4 expression on CBMC was significantly lower than that in adult monocytes, suggesting neonatal monocytes are more immature than adult monocytes (28).

To further characterize the differences between neonate and adult in their monocyte subpopulations, function, and differentiation, we studied their $\mathrm{CD} 14^{+} \mathrm{CD} 4^{+}$and $\mathrm{CD} 14^{+} \mathrm{CD} 16^{+}$ subpopulations, production of IL- $1 \beta$ and TNF- $\alpha$ induced by LPS, and their phenotype development in CD14 and CD1a in response to IL-4 or GM-CSF or both. To date, the regulatory effects of IL-4 and GM-CSF on the CD14 and CD1a expression in cord blood have not been reported.

\section{METHODS}

Isolation of MNC. Human umbilical cord blood was obtained from the placentas of normal, full-term infants, after the placentas were delivered and separated from the infants, with prior written informed consent of their parents. The protocol was approved by the Ethics Committee of the University of Hong Kong. Adult peripheral blood was obtained from healthy adult volunteers from 20 to $35 \mathrm{y}$ of age. All samples were collected in heparinized flasks. Umbilical CBMC and adult PBMC were isolated from whole blood by centrifugation, using Ficoll-Hypaque gradients (Pharmacia Biotech, Uppsala, Sweden). The MNC at the interface were collected, washed three times, and resuspended at a density of $1 \times 10^{6}$ cells $/ \mathrm{mL}$ in a serum- and hormone-free medium [Dulbecco's Modified Eagle's Medium Nutrient Mixture F-12 Ham (DMEM/F12); Sigma Chemical Co, St. Louis, MO, U.S.A.], which did not contain insulin, IGF-1, or other hormones, supplemented with $50 \mathrm{IU} / \mathrm{mL}$ penicillin and $50 \mu \mathrm{g} / \mathrm{mL}$ streptomycin (Life Technologies, Grand Island, NY, U.S.A.). Cell viability, as determined by trypan blue exclusion, was $>95 \%$.

Culture of MNC in vitro. A total of $1 \times 10^{6} \mathrm{MNC}$ were cultured in the presence or absence of LPS $(10 \mu \mathrm{g} / \mathrm{mL}$; Sigma) for $3 \mathrm{~d}$, with or without IL-4 (10 ng/mL; R\&D Systems Inc, Minneapolis, MN, U.S.A.) or GM-CSF (50 ng/mL; R\&D Systems), and incubated for varying periods of 3, 6, or $9 \mathrm{~d}$ at $37^{\circ} \mathrm{C}$ in a humidified atmosphere containing $5 \% \mathrm{CO}_{2}$. The cultures were fed with fresh serum-free DMEM-F12 medium and cytokines every $3 \mathrm{~d}$, and cell differentiation was monitored by light microscopy.
Immunofluorescence staining. Cells were collected from the wells by the addition of trypsin EDTA (Life Technologies) and gentle scraping at the defined time (d 3,6, and 9). Cells were transferred to microcentrifuge tubes diluted with $1 \mathrm{~mL}$ of PBS and centrifuged at $13,000 \times g$ for $10 \mathrm{~s}$. The supernatant was removed, and the cell pellets were resuspended in the small amount of remaining PBS. Fluorochrome-conjugated antibodies at concentrations of $4 \mu \mathrm{g} / 10^{6}$ cells were added, and the cell suspension was incubated in the dark for $15 \mathrm{~min}$ at room temperature. After incubation, the cells were diluted in 1 $\mathrm{mL}$ of wash solution (PBS plus $0.1 \%$ fetal bovine serum plus $0.1 \%$ azide), and after centrifugation and the removal of supernatant, the cells were resuspended in $300 \mu \mathrm{L}$ of the same solution for flow cytometric analysis. FITC- and PC5conjugated isotype controls, CD14-FITC and CD4-PC5, were from Immunotech (Marseille, Cedex, France), and CD16-PC5 and CD1a-PC5 were from PharMingen (San Diego, CA, U.S.A.).

Signal analysis. Flow cytometric analysis was performed with a Coulter Epicselite Flow Cytometer (Coulter Corporation, Miami, FL, U.S.A.). The machine was optimized daily using standard fluorescence beads (Coulter Corporation). Ten thousand events per sample were collected into listmode files and analyzed by WinMDI 2.8 analysis software. The analysis in this study is based on a population of cells in the live gate with high forward scatter and high side scatter. This population of interest mainly representing monocytes is clearly separate from the lymphoid population. The gating strategy is consistent throughout the study. The fluorescence level of FITC was standardized by Quantum 25 beads (Flow Cytometry Standards Corp, San Juan, PR, U.S.A.) and converted to kMESF (mean equivalent soluble fluorochrome, in thousands).

ELISA for IL-1 $\beta$ and TNF- $\alpha$. Concentration of IL-1 $\beta$ and TNF- $\alpha$ in culture supernatants was measured by specific ELISA assays with commercial ELISA kits (R\&D Systems) according to the manufacturer's instructions. Each sample was measured in duplicate. Minimal detectable levels of IL-1 $\beta$ and TNF- $\alpha$ were $3.91 \mathrm{pg} / \mathrm{mL}$ and $15.6 \mathrm{pg} / \mathrm{mL}$, respectively.

Statistical methods. All data are expressed as mean \pm SEM. ANOVA was used to examine the influence of different time of culture and culture conditions on the percentage of $\mathrm{CD} 14^{+}$and $\mathrm{CD}^{+}{ }^{+}$cells for $\mathrm{CBMC}$ or adult PBMC. Tukey multiple comparison test was used to examine the percentage in $\mathrm{CD} 14^{+}$ or $\mathrm{CD} \mathrm{a}^{+}$cells among groups. To determine the difference between paired or unpaired groups, the $t$ test or the MannWhitney $U$ statistic was used.

\section{RESULTS}

Reduced percentage of $\mathrm{CD}_{14}^{+}$monocytes and decreased level of CD14 expression in cord blood. The percentage of $\mathrm{CD} 14^{+}$cells in our population of interest in freshly isolated CBMC $(40 \pm 4 \%, n=18)$ was significantly lower than that in adult PBMC $(65 \pm 3 \%, n=18, p<0.01)$. The level of CD14 expression in monocytes was significantly lower in CBMC $(268 \pm 19 \mathrm{kMESF}, n=8)$ than that in adult PBMC $(342 \pm 14$ kMESF, $n=10, p<0.01$; Fig. 1 ). 

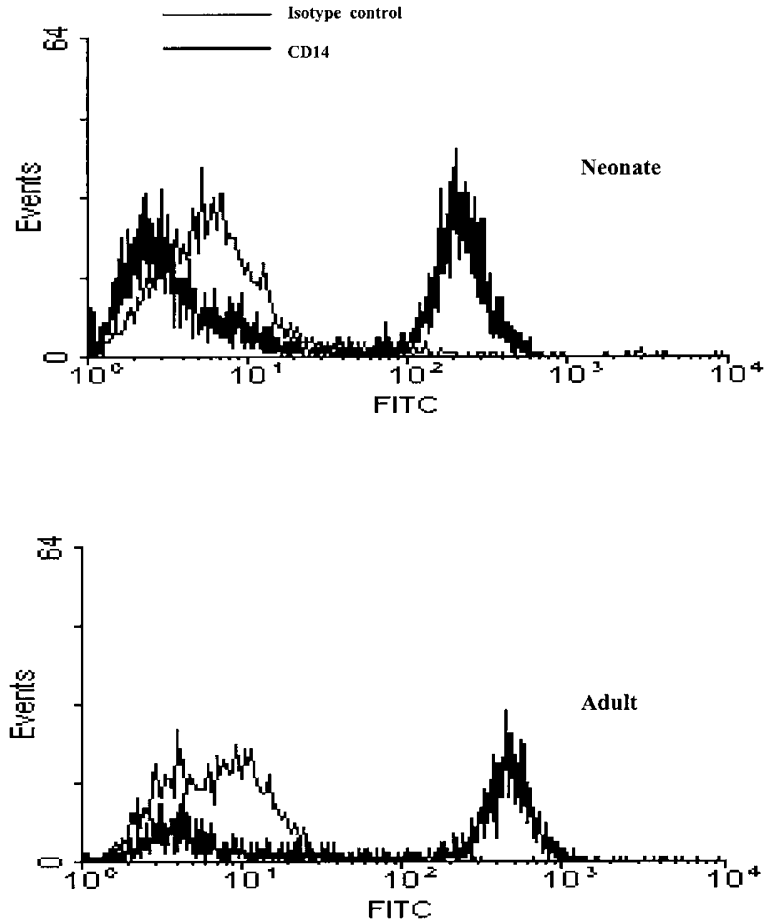

Figure 1. The expression levels of CD14 in a representative case of CBMC (Top) and adult PBMC (Bottom). The difference of CD14 expression levels between CBMC (268 $\pm 19 \mathrm{kMESF}, n=8)$ and adult PBMC $(342 \pm 14$ kMESF, $n=10)$ was significant $(p<0.01)$. Results are expressed as mean \pm SEM.

Decreased $\mathrm{CD}_{14}^{+} \mathrm{CD}^{+}{ }^{+}$and $\mathrm{CD} 14^{+} \mathrm{CD} 4^{+}$monocytes among $\mathrm{CD}_{14^{+}}$population in cord blood. Using two-color flow cytometric analysis, we assessed the percentage of $\mathrm{CD} 14^{+} \mathrm{CD} 4^{+}$and $\mathrm{CD} 14^{+} \mathrm{CD} 16^{+}$cells among the $\mathrm{CD} 14^{+}$ population in $\mathrm{CBMC}$ and PBMC (Fig. 2). The percentage of $\mathrm{CD} 14^{+} \mathrm{CD} 4^{+}$cells among the $\mathrm{CD} 14^{+}$population in CBMC $(6$ $\pm 1 \%, n=8)$ was significantly lower than that in PBMC (16 $\pm 3 \%, n=8, p<0.05$ ). Similarly, the percentage of $\mathrm{CD} 14^{+} \mathrm{CD} 16^{+}$cells among the $\mathrm{CD} 14^{+}$population in CBMC $(16 \pm 2 \%, n=9)$ was also significantly lower than that in PBMC $(24 \pm 3 \%, n=14, p<0.05)$.

Decreased IL-1 $\beta$ and $T N F-\alpha$ production from CBMC. After $3 \mathrm{~d}$ of serum-free culture in the presence of $10 \mu \mathrm{g} / \mathrm{mL}$ of LPS, CBMC produced significantly lower IL- $1 \beta$ and TNF- $\alpha$ than adult PBMC (IL- $1 \beta, 463 \pm 49 \mathrm{pg} / \mathrm{mL}$ versus $585 \pm 39$ $\mathrm{pg} / \mathrm{mL}, p<0.05$; TNF- $\alpha, 448 \pm 95 \mathrm{pg} / \mathrm{mL}$ versus $784 \pm 29$ $\mathrm{pg} / \mathrm{mL}, p<0.01$; Fig. 3). Thus, the CBMC production of IL- $1 \beta$ in response to LPS stimulation was $79 \%$ of the level produced by adult PBMC, whereas the corresponding result for TNF- $\alpha$ was $57 \%$. Take together, the results indicated a deficiency in CBMC to respond to cellular stress signals such as LPS.

Down-regulation of the CD14 $14^{+}$population by $I L-4$ and $\boldsymbol{G M}$-CSF. The kinetics of $\mathrm{CD}_{14}{ }^{+}$monocyte development in adult PBMC and CBMC are summarized in Figure 4. When cultured in medium alone, the percentage of $\mathrm{CD} 14^{+}$monocytes in adult PBMC decreased from $65 \pm 3 \%$ to $37 \pm 8 \%$ after $3 \mathrm{~d}$ of culture, then increased slightly by d $6(54 \pm 12 \%)$, and maintained at approximately the same level at $47 \pm 6 \%$ on

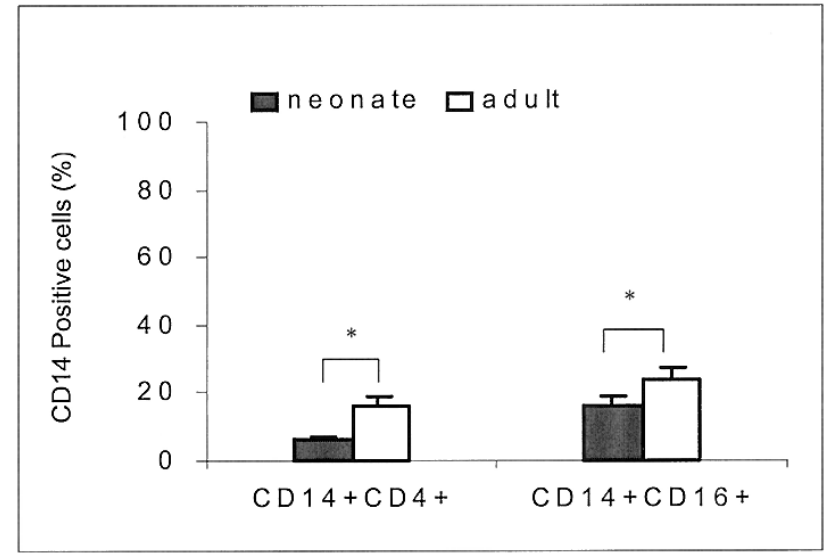

Figure 2. The percentages of the $\mathrm{CD} 4^{+}$and $\mathrm{CD} 16^{+}$subpopulations among $\mathrm{CD} 4^{+}$monocytes in cord blood and adult peripheral blood. Both the percentages of $\mathrm{CD} 14^{+} \mathrm{CD} 4^{+}$and $\mathrm{CD} 14^{+} \mathrm{CD} 16^{+}$monocytes between cord blood $(n=$ 8 and 9 , respectively) and adult peripheral blood ( $n=8$ and 14, respectively) were significantly different $(p<0.05)$. Results are expressed as mean \pm SEM.

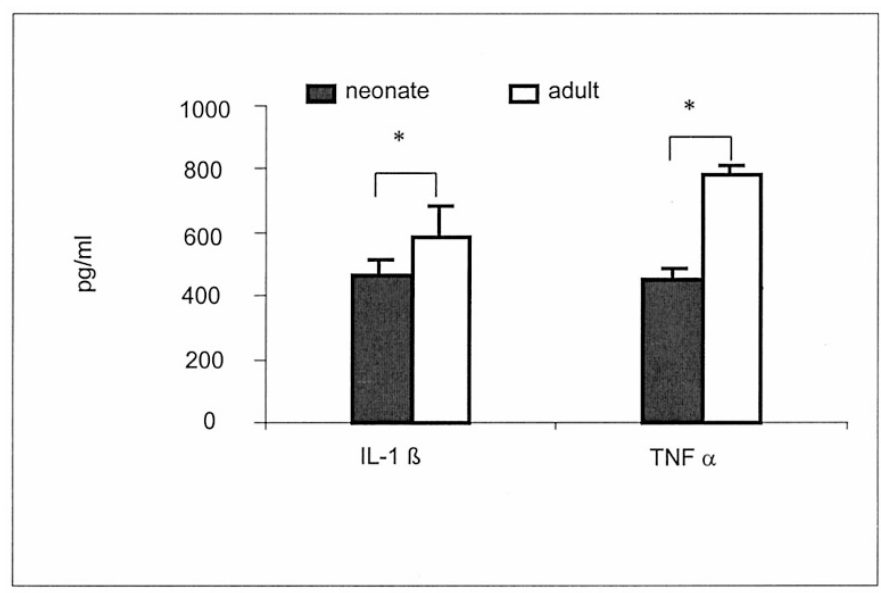

Figure 3. Production of IL- $1 \beta$ and TNF- $\alpha$ by CBMC and adult PBMC in vitro. After stimulation by LPS for $3 \mathrm{~d}$, the production of IL- $1 \beta$ and TNF- $\alpha$ in the supernatants of PBMC $(n=10)$ and CBMC $(n=9)$ were assayed by ELISA. Significant differences in production of both IL- $1 \beta$ and TNF- $\alpha$ between CBMC and PBMC were found $(p<0.05)$. Results are expressed as mean \pm SEM.

d 9. In the presence of IL-4 and IL-4 plus GM-CSF, the percentage of $\mathrm{CD}_{1} 4^{+}$monocytes in adult PBMC decreased significantly to $17 \pm 9 \%$ and $15 \pm 8 \%$, respectively $(p<$ 0.01 ), and the percentage of $\mathrm{CD} 14^{+}$monocytes progressively decreased to zero through $9 \mathrm{~d}$ of culture. In the presence of GM-CSF alone, there was a rapid decrease in the percentage of $\mathrm{CD} 4^{+}$monocytes by $\mathrm{d} 3$ to $26 \pm 11 \%$, which was then maintained at approximately the same levels on d 6 (35 \pm $13 \%)$ and $\mathrm{d} 9(21 \pm 7 \%)$.

In contrast, the percentage of $\mathrm{CD}_{1} 4^{+}$monocytes in cord blood was maintained for $3 \mathrm{~d}$ under all study conditions (medium, $49 \pm 4 \%$; IL-4, $37 \pm 5 \%$; GM-CSF, $45 \pm 4 \%$; IL-4 plus GM-CSF, $36 \pm 5 \%$ ). By d 6 of culture, the percentage of $\mathrm{CD} 14^{+}$monocytes became divergent under culture conditions with different cytokine treatment. In the control cells without any cytokine treatment, there was a gradual increase through 
$9 \mathrm{~d}$ of culture to a level of $67 \pm 8 \%$ (Fig. $4 B$ ), which was comparable to that of the corresponding controls in adult PBMC (Fig. 4A). IL-4 significantly reduced the percentage of $\mathrm{CD} 14^{+}$monocytes to $12 \pm 5 \%$ on $\mathrm{d} 6$, and then to $5 \pm 3 \%$ on d 9, whereas IL-4 plus GM-CSF in combination could reduce the percentage of $\mathrm{CD} 14^{+}$monocytes even more to $11 \pm 5 \%$ on d 6 , and then to $2 \pm 1 \%$ on $\mathrm{d} 9$. GM-CSF had similar effects to IL-4 in reducing the percentage of $\mathrm{CD} 14^{+} \mathrm{CBMC}$ from $\mathrm{d} 6$ to $\mathrm{d} 9$ but to a lesser degree $(\mathrm{d} 6,23 \pm 9 \%$; $9,14 \pm 7 \%$; Fig. $4 B)$.

Up-regulation of CD1a ${ }^{+}$population by $I L-4$ and GM-CSF . For adult peripheral blood, IL-4 alone or IL-4 plus GM-CSF started to up-regulate $\mathrm{CD} 1 \mathrm{a}^{+}$expression on monocytes by $\mathrm{d} 6$ (IL-4, $7 \pm 4 \%, n=5$; IL-4 plus GM-CSF, $8 \pm 4 \%, n=5$ ) and

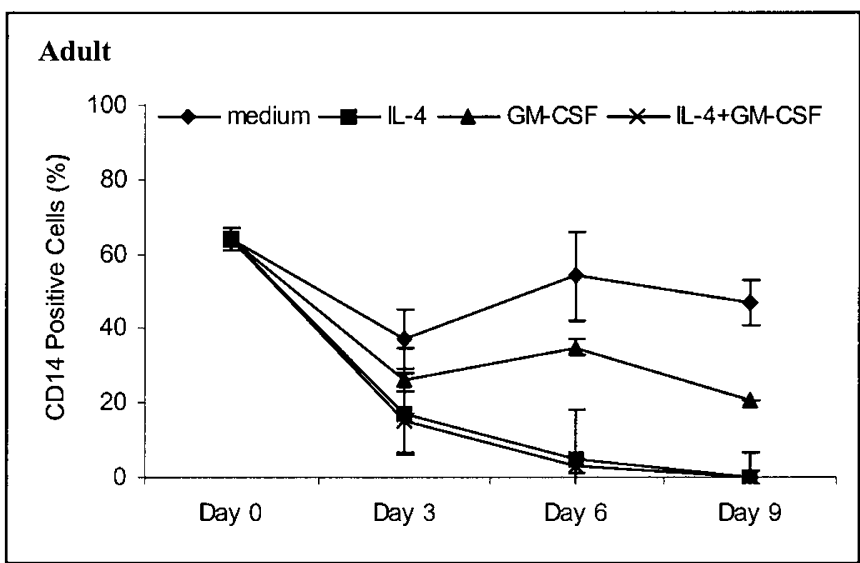

A

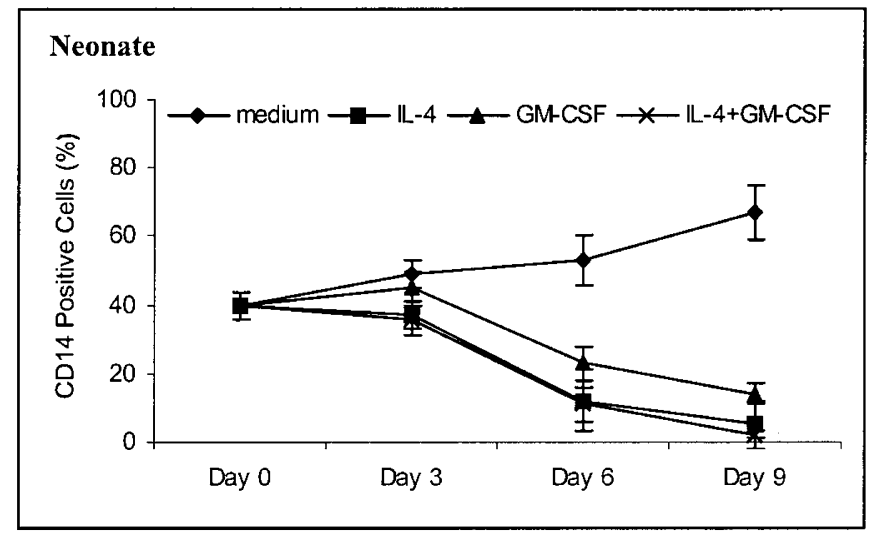

B

Figure 4. Change of the percentages of $\mathrm{CD} 14^{+}$monocytes in adult blood and cord blood cultured in different conditions. The percentages of $\mathrm{CD} 14^{+}$monocytes incubated with medium alone and cytokines were evaluated by flow cytometry at $\mathrm{d} 0,3,6$, and 9 , and the percentages (mean \pm SEM) are shown. $A$, for adult PBMC, in the presence of IL-4 $(n=5)$ and IL-4 plus GM-CSF $(n=5)$, the percentages of $\mathrm{CD} 14^{+}$monocytes decreased significantly compared with medium alone $(p<$ $0.01) . B$, in contrast, the percentages of $\mathrm{CD} 14^{+}$monocytes in $\mathrm{CBMC}$ were maintained after $3 \mathrm{~d}$ of culture in the presence IL- $4(n=8), \operatorname{GM}-\operatorname{CSF}(n=8)$, and IL-4 plus GM-CSF $(n=8)$. On d 6, there was a significant reduction of CD14 ${ }^{+}$ monocytes in CBMC cultured with IL-4 $(n=8)$ or IL-4 plus GM-CSF $(n=10$; $p<0.01$ ), whereas the percentage of $\mathrm{CD} 14^{+}$monocytes increased in culture with medium alone $(p<0.05)$. GM-CSF $(n=8)$ alone continued to down-regulate $\mathrm{CD} 14^{+}$monocytes in CBMC through $9 \mathrm{~d}$ of culture $(p<0.05)$. reached a plateau by d 9 (IL-4, $7 \pm 3 \%, n=5$; IL-4 plus GM-CSF, $8 \pm 2 \%, n=5)$. $\mathrm{CD}^{+} \mathrm{a}^{+}$expression on adult PBMC did not change with GM-CSF alone or medium alone (Fig. $5 A$ ).

For cord blood, both IL-4 and IL-4 plus GM-CSF upregulated CD1a expression on monocytes but with different kinetics and degree of up-regulation (d 6: $7 \pm 5 \%, n=8 ; 13$ $\pm 5 \%, n=10$, respectively; d 9: $14 \pm 4 \%, n=8 ; 29 \pm 7 \%$, $n=10$, respectively; Fig. $5 B$ ). Compared with adult monocytes, the $\mathrm{CD} \mathrm{a}^{+}$population was much higher in CBMC by d 9 of culture (neonate, $29 \pm 7 \%$ versus adult, $8 \pm 2 \%$; $p<$ 0.01 ), and the cord blood $\mathrm{CD} 1 \mathrm{a}^{+}$population had not apparently reached a plateau under the stimulation of IL-4 or IL-4 plus GM-CSF.

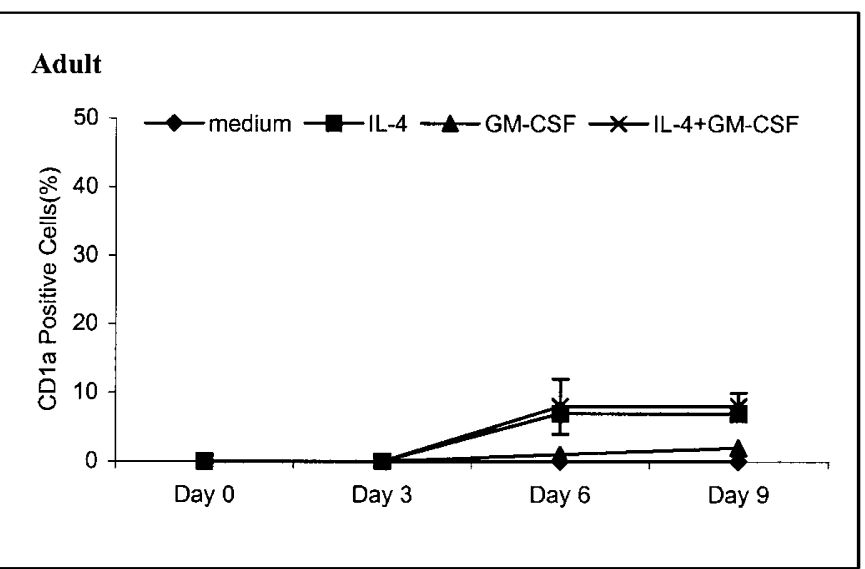

A

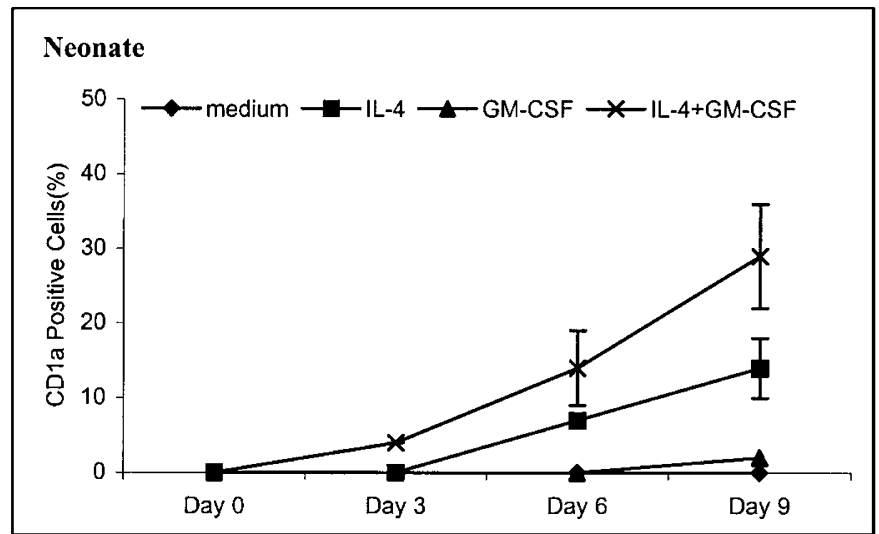

B

Figure 5. The kinetics of change of the percentages of the $\mathrm{CD} 1 \mathrm{a}^{+}$monocytes in adult blood and cord blood cultured in different conditions. The percentages of CD1 ${ }^{+}$monocytes in PBMC and CBMC incubated with medium alone and cytokines were evaluated by flow cytometry at $\mathrm{d} 0,3,6$, and 9 , and the mean percentages are shown. $A$, in the presence of IL-4 $(n=5)$ or IL-4 plus GM-CSF $(n=5)$, the percentages of $\mathrm{CD} \mathrm{a}^{+}$monocytes in PBMC increased significantly from d 3 to $\mathrm{d} 6(p<0.05)$, reached a plateau by $\mathrm{d} 6$, and were maintained at that level through d $9(p>0.05) . B$, for CBMC, in the presence of IL-4 $(n=8)$ or IL-4 plus GM-CSF $(n=10)$, the percentages of CD1a ${ }^{+}$ monocytes increased through the $9 \mathrm{~d}$ of culture with no plateau reached $(p<$ $0.05)$. Results are expressed as mean \pm SEM. 


\section{DISCUSSION}

Neonates are relatively immature in their innate immunity, and our results showed that the expression of CD14 both in terms of percentage and intensity on CBMC was significantly lower than that on adult PBMC, in keeping with the study by Kampalath et al. (28), who found that the mean fluorescence intensity of CD14 expression was slightly higher on adult PBMC than on CBMC. As a key molecule in innate immunity, CD14 plays a major role in the recognition of LPS of Gramnegative bacteria (3). There is increasing evidence that CD14 also serves as a receptor for other microbial products including peptidoglycan of Gram-positive bacteria (29). Furthermore, we have shown that IL- $1 \beta$ and TNF- $\alpha$ production induced by LPS in CBMC were significantly lower than that in adult PBMC (Fig. 3). The lower CD14 expression in CBMC may result in a lower response toward LPS and even other Gram-positive pathogens.

There is differential expression of function related antigens on CBMC and adult PBMC (30), and it has been reported that the reduction of $\mathrm{CD}^{+}$expression is related to the immaturity of neonatal monocytes (28). Our results showed that the percentage of $\mathrm{CD}^{+}$cells among the $\mathrm{CD} 14^{+}$population in $\mathrm{CBMC}$ was significantly lower than that in adult PBMC. The percentage of $\mathrm{CD} 14^{+} \mathrm{CD} 16^{+}$in $\mathrm{CBMC}$ was also lower than that in PBMC (Fig. 2). The lower percentages of $\mathrm{CD} 14^{+} \mathrm{CD} 4^{+}$and $\mathrm{CD} 14^{+} \mathrm{CD} 16^{+}$monocyte subpopulation in cord blood suggest a less mature monocyte phenotype in neonates.

The regulation of CD14 is related to the function and differentiation of monocytes. LPS can up-regulate monocyte CD14 expression, which in turn is related to the anti-apoptotic effect of LPS on monocytes (8-10). IL-4 can down-regulate monocyte CD14, which is related to its apoptotic effect on monocytes (5). GM-CSF is a well-known stimulus for the activation, differentiation, and survival of monocytes. GM-CSF can reduce the CD14 expression of PBMC after $3 \mathrm{~d}$ of culture (11). When monocytes were cultured for $7 \mathrm{~d}$ with GM-CSF and serum, CD14 was, however, up-regulated, leading to a higher sensitivity toward LPS stimulation (31). These conflicting results can in part be explained by the various culture conditions used.

A combination of IL-4 and GM-CSF has been used to generate DC from PBMC (12) with changes in phenotypes and function. We therefore used IL-4 and GM-CSF to assess the difference of in vitro differentiation of monocytes into DC between cord blood and adult peripheral blood in terms of phenotypic changes in CD1a and CD14. In our system, the kinetics of percentage change of $\mathrm{CD} 14^{+}$monocytes in CBMC for $9 \mathrm{~d}$ of culture differed from that of adult PBMC. After $3 \mathrm{~d}$ of culture, significant down-regulation of $\mathrm{CD} 14^{+}$monocytes was found either spontaneously or cultured with IL-4, GMCSF, or IL-4 plus GM-CSF in adult PBMC, but not in CBMC (Fig. 4). It was only after $6 \mathrm{~d}$ of culture that down-regulation of CD14 expression became evident in CBMC, demonstrating the different kinetic responses to IL-4 and GM-CSF between CBMC and adult PBMC. The mechanism and significance of the different kinetics of down-regulation of CD14 expression between $\mathrm{CBMC}$ and adult PBMC are not yet clear. The slower phenotypic change of $\mathrm{CD} 14^{+}$expression in cord blood may be related to the less mature stage of CBMC compared with adult PBMC. We and others have shown that neonatal monocytes are phenotypically less mature than adult monocytes (28). Down-regulation of CD14 expression might represent a rapid adaptation of the host to stress (11). Hence, slower downregulation of $\mathrm{CD} 14$ expression in cord blood implies that the ability of adaptation to stress of CBMC is less than that of adult monocytes when challenged.

CD1a belongs to the CD1 family, which is a family of glycoproteins encoded by five genes located on chromosome 1 in man (32). Resembling that of MHC class II molecules, CD1 molecules could participate in antigen presentation, especially presenting lipids or glycolipids from mycobacterium (33). Moreover, it is reported that the human CD1a molecule expressed on monocytes plays an accessory role in the superantigen-induced activation of T cells (34). GM-CSF can increase CD1 molecule expression on human monocytes (35). In our study, IL-4 and GM-CSF could increase the percentage of $\mathrm{CD}^{+}{ }^{+}$monocytes in both CBMC and adult PBMC, whereas CD14 expression was down-regulated. Again the kinetics of percentage change of $\mathrm{CD} \mathrm{a}^{+}$monocytes in CBMC during $9 \mathrm{~d}$ of culture differed from that of adult PBMC. The percentage of $\mathrm{CD} 1 \mathrm{a}^{+}$monocytes in CBMC cultured with IL-4 plus GM-CSF for $9 \mathrm{~d}$ was significantly more increased $(29 \pm 7 \%)$ than that in adult PBMC $(8 \pm 2 \%$; Fig. 5$)$. This observation seemed to be in conflict with slower kinetics of CD14 down-regulation in CBMC than that of adult monocytes, as differentiation of monocytes into DC was characterized by down-regulation of $\mathrm{CD} 14$ expression with up-regulation of $\mathrm{CD} 1 \mathrm{a}$ expression and we should expect comparable kinetics of change for these two phenotypes. Inasmuch as the mixed-cell population was used in our system, the different CD1a expression in response to IL-4 and GM-CSF between CBMC and adult PBMC may be related to interaction between monocytes and lymphocytes. It is possible that higher ability of cytokine production, such as IL-10, from adult PBMC than from CBMC can down-regulate CD1a expression in adult monocytes $(36,37)$. With purified $\mathrm{CD}_{14}{ }^{+}$monocytes, we have shown that the ability of CBMC to differentiate to $\mathrm{CD} 1 \mathrm{a}^{+}$immature $\mathrm{DC}$ in response to IL-4 and GM-CSF was significantly lower than that of adult PBMC (data not shown). This result further confirmed that the downregulation of CD14 expression of monocytes was associated with up-regulation of CD1a expression on immature DC under the stimulation of IL-4 and GM-CSF. Further study on purified monocytes of adult and cord blood is in progress.

We concluded that the immaturity of neonatal immunity may be related to the reduction of $\mathrm{CD} 14^{+} \mathrm{CD} 4^{+}$and $\mathrm{CD} 14^{+} \mathrm{CD} 16^{+}$monocyte subpopulations as well as the lower percentage and lower intensity of CD14 expression. This is further connected to the lower response of CBMC in production of IL- $1 \beta$ and TNF- $\alpha$ to LPS. The discrepancy in the kinetics of CD14 down-regulation between CBMC and adult PBMC on stimulation by IL-4 and GM-CSF may be related to their different differentiation stages, with CBMC being less mature, hence taking a longer time to down-regulate CD14. Slower down-regulation of CD14 with IL-4 and GM-CSF may 
result in a lower or slower adaptation to stress compared with that of adult PBMC.

Acknowledgments. The authors thank the staff from ward A6, Queen Mary Hospital, in facilitating the collection of cord blood. We also thank the volunteers in the Department of Pediatrics, The University of Hong Kong, in donating their blood for this study.

\section{REFERENCES}

1. Landmann R, Muller B, Zimmerli W 2000 CD14, new aspects of ligand and signal diversity. Microbes Infect 2:295-304

2. Haziot A, Chen S, Ferrero E, Low MG, Silber R, Goyert SM 1988 The monocyte differentiation antigen, CD14, is anchored to the cell membrane by a phosphatidylinositol linkage. J Immunol 141:547-552

3. Wright SD, Ramos RA, Tobias PS, Ulevitch RJ, Mathison JC 1990 CD14, a receptor for complexes of lipopolysaccharide (LPS) and LPS binding protein. Science 249:1431-1433

4. Dentener MA, Bazil V, Von Asmuth EJ, Ceska M, Buurman WA 1993 Involvemen of CD14 in lipopolysaccharide-induced tumor necrosis factor-alpha, IL-6 and IL-8 release by human monocytes and alveolar macrophages. J Immunol 150:2885-2891

5. Heidenreich S, Schmidt M, August C, Cullen P, Rademaekers A, Pauels HG 1997 Regulation of human monocyte apoptosis by the CD14 molecule. J Immuno 159:3178-3188

6. Devitt A, Moffatt OD, Raykundalia C, Capra JD, Simmons DL, Gregory CD 1998 Human CD14 mediates recognition and phagocytosis of apoptotic cells. Nature 392:505-509

7. Landmann R, Ludwig C, Obrist R, Obrecht JP 1991 Effect of cytokines and lipopolysaccharide on CD14 antigen expression in human monocytes and macrophages. J Cell Biochem 47:317-329

8. Landmann R, Knopf HP, Link S, Sansano S, Schumann R, Zimmerli W 1996 Human monocyte CD14 is upregulated by lipopolysaccharide. Infect Immun 64:1762-1769

9. Ruppert J, Friedrichs D, Xu H, Peters JH 1991 IL-4 decreases the expression of the monocyte differentiation marker CD14, paralleled by an increasing accessor potency. Immunobiology 182:449-464

10. Lauener RP, Goyert SM, Geha RS, Vercelli D 1990 Interleukin 4 down-regulates the expression of CD14 in normal human monocytes. Eur J Immunol 20:2375-2381

11. Kruger M, Van de Winkel JG, De Wit TP, Coorevits L, Ceuppens JL 1996 Granulocyte-macrophage colony-stimulating factor down-regulates CD14 expression on monocytes. Immunology 89:89-95

12. Chapuis F, Rosenzwajg M, Yagello M, Ekman M, Biberfeld P, Gluckman JC 1997 Differentiation of human dendritic cells from monocytes in vitro. Eur J Immuno 27:431-441

13. Wang SY, Mak KL, Chen LY, Chou MP, Ho CK 1992 Heterogeneity of human blood monocyte: two subpopulations with different sizes, phenotypes and function. Immunology 77:298-303

14. Passlick B, Flieger D, Ziegler-Heitbrock HW 1989 Identification and characterization of a novel monocyte subpopulation in human peripheral blood. Blood 74:2527-2534

15. Deo YM, Graziano RF, Repp R, van de Winkel JG 1997 Clinical significance of IgC Fc receptors and Fc gamma R-directed immunotherapies. Immunol Today 18:127135

16. Ziegler-Heitbrock HW 1996 Heterogeneity of human blood monocytes: the CD14 $\mathrm{CD}^{+} 6^{+}$subpopulation. Immunol Today 17:424-428
17. Szabo G, Miller CL, Kodys K 1990 Antigen presentation by the CD4 positive monocyte subset. J Leukoc Biol 47:111-120

18. Wilson CB, Lewis DB 1990 Basis and implications of selectively diminished cytokine production in neonatal susceptibility to infection. Rev Infect Dis 12(suppl 4):S410-S420

19. Tu W, Cheung PT, Lau YL 1999 IGF-I increases interferon-gamma and IL-6 mRNA expression and protein production in neonatal mononuclear cells. Pediatr Res $46: 748-754$

20. Tu W, Cheung PT, Lau YL 2000 Insulin-like growth factor 1 promotes cord blood T cell maturation and inhibits its spontaneous and phytohemagglutinin-induced apoptosis through different mechanisms. J Immunol 165:1331-1336

21. Orlowski JP, Sieger L, Anthony BF 1976 Bactericidal capacity of monocytes of newborn infants. J Pediatr 89:797-801

22. Weston WL, Carson BS, Barkin RM, Slater GD, Dustin RD, Hecht SK 1977 Monocyte-macrophage function in the newborn. Am J Dis Child 131:1241-1242

23. Prindull G, Prindull B, Palti Z, Yoffey JM 1975 Phagocytic cells in cord blood. Biol Neonate 27:318-328

24. Klein RB, Fischer TJ, Gard SE, Biberstein M, Rich KC, Stiehm ER 1977 Decreased mononuclear and polymorphonuclear chemotaxis in human newborns, infants, and young children. Pediatrics 60:467-472

25. Dretschmer RR, Stewardson RB, Papierniak CK, Gotoff SP 1976 Chemotactic and bactericidal capacities of human newborn monocytes. J Immunol 117:1303

26. Mawas F, Wiener E, Ryan G, Soothill PW, Rodeck CH 1994 The expression of IgG Fc receptors on circulating leucocytes in the fetus and new-born. Transfus Med 4:25-33

27. Maeda M, van Schie RC, Yuksel B, Greenough A, Fanger MW, Guyre PM, Lydyard PM 1996 Differential expression of Fc receptors for IgG by monocytes and granulocytes from neonates and adults. Clin Exp Immunol 103:343-347

28. Kampalath B, Cleveland RP, Kass L 1998 Reduced CD4 and HLA-DR expression in neonatal monocytes. Clin Immunol Immunopathol 87:93-100

29. Weidemann B, Schletter J, Dziarski R, Kusumoto S, Stelter F, Rietschel ET, Flad HD, Ulmer AJ 1997 Specific binding of soluble peptidoglycan and muramyldipeptide to CD14 on human monocytes. Infect Immun 65:858-864

30. Murphy FJ, Reen DJ 1996 Differential expression of function-related antigens on newborn and adult monocyte subpopulations. Immunology 89:587-591

31. Kreutz M, Hennemann B, Ackermann U, Grage-Griebenow E, Krause SW, Andreesen R 1999 Granulocyte-macrophage colony-stimulating factor modulates lipopolysaccharide (LPS)-binding and LPS-response of human macrophages: inverse regulation of tumour necrosis factor-alpha and interleukin-10. Immunology 98:491496

32. Yu CY, Milstein C A 1989 Physical map linking the five CD1 human thymocyte differentiation antigen genes. EMBO J 8:3727-3732

33. Schaible UE, Hagens K, Fischer K, Collins HL, Kaufmann SH 2000 Intersection of group I CD1 molecules and mycobacteria in different intracellular compartments of dendritic cells. J Immunol 164:4843-4852

34. Gregory S, Zilber M, Charron D, Gelin C 2000 Human CD1 a molecule expressed on monocytes plays an accessory role in the superantigen-induced activation of $\mathrm{T}$ lymphocytes. Hum Immunol 61:193-201

35. Kasinrerk W, Baumruker T, Majdic O, Knapp W, Stockinger H 1993 CD1 molecule expression on human monocytes induced by granulocyte-macrophage colonystimulating factor. J Immunol 150:579-584

36. Chheda S, Palkowetz KH, Garofalo R, Rassin DK, Goldman AS 1996 Decreased interleukin-10 production by neonatal monocytes and $\mathrm{T}$ cells: relationship to decreased production and expression of tumor necrosis factor-alpha and its receptors. Pediatr Res 40:475-483

37. Allavena P, Piemonti L, Longoni D, Bernasconi S, Stoppacciaro A, Ruco L, Mantovani A 1998 IL-10 prevents the differentiation of monocytes to dendritic cells but promotes their maturation to macrophages. Eur J Immunol 28:359-369 